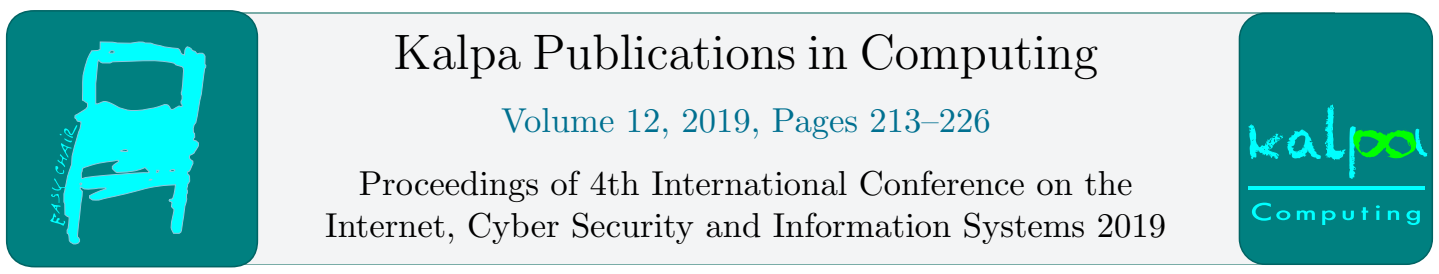

\title{
A Data-Driven Decision-Making Model for the Third-Party Logistics (3PL) Industry
}

\author{
Faith Moyo ${ }^{1}$, Brenda Scholtz ${ }^{1}$, Mohammed Alhassan ${ }^{1}$ \\ ${ }^{1}$ Nelson Mandela University, Port Elizabeth 6001, South Africa \\ s212229044@mandela.ac.za, Brenda.Scholtz@mandela.ac.za, \\ s220019843@mandela.ac.za
}

\begin{abstract}
The evolution of the supply chain has resulted in a growth in the usage of technology and data generated and distributed within the industry. Third-party logistics (3PL) companies operating within the supply chain industry are not maximising the capabilities of data to make wellinformed decisions. The purpose of this paper is to address this gap and to develop a prescriptive, theoretical model for data-driven decision-making (DDDM). To address the gap, a literature review of DDDM in 3PL industry and in other contexts was conducted. The proposed model is built based on the consideration of existing DDDM models and frameworks; data and data analytics principles to collect, store, manage and analyse data; and the Cynefin framework. Existing models and frameworks for DDDM do not provide explicit guidelines on how to apply DDDM in a 3PL and supply chain context. The proposed DDDM model constitutes of three phases, namely: (1) the setup phase, that considers data knowledge and decision-making knowledge; (2) execution phase; and (3) the learning phase. The application of the model in 3PL companies can support the decisionmaking process in these companies, with a consideration of the challenges and opportunities that exist in the supply chain. The decision-makers in 3PLs can thus make better-informed decisions that positively impact their enterprises and the supply chain.
\end{abstract}

Keywords: Supply Chain Industry, Third-Party Logistics, Data-Driven Decision-Making, Prescriptive Model, Cynefin Framework, Data Analytics.

\section{$1 \quad$ Introduction}

Emerging technologies such as mobile devices, personal computers, drones, wearable devices, and smartphones have altered the way societies access and exchange information [1]. In the supply chain and the third-party logistics (3PLs) industries, an evolution in operations has taken place due to emerging technologies, automation and digitisation [2]. Information Systems (IS) are enabling the collection and generation of large amounts of data; thus there is a pressing need for supply chain players to stay ahead of their competitors by turning the data into actionable insights [3]. However, 3PLs and other companies in the supply chain industry have not maximised the capabilities of data to transform, 
operate and manage their respective enterprises [4], and to extract actionable insights that could assist 3PLs and other supply chain players with making well-informed decisions [5]. These insights cannot be extracted solely from the use of technology to analyse the data; the processes of decision-making must be considered as well as the knowledge of the decision-makers [6].

Modern theories of the value of information begin with the seminal work of Blackwell [7]. Blackwell's theorem states that decision-makers observe signals correlated to the state of their environments prior to their choice of action and hence "update" the probability distribution before the "optimal" action is chosen. Therefore, instead of relying on their instincts, enterprise leaders gather relevant data sets and perform various data analysis activities to make sound decisions that are based on scientific signals and observations [8]. Data provides insights on how to answer key enterprise questions [9]. In making decisions with uncertainty, enterprises should be able to classify the data collected to build a suitable model for mitigating the risk of misinterpreting the data [10]. The collected data must be in accordance with the objectives to be achieved by the enterprise, therefore increasing the reliance that can be placed on the data analytics models derived [11]. The act of basing decisions on the analysis of data rather than purely on intuition is referred to as Data-Driven Decision-Making (DDDM) [12].

The research objectives of this study are: (1) to determine existing frameworks and models for DDDM; and (2) to determine the requirements of decision-making for the 3PL and supply chain domain and the suitability of existing models/frameworks. The purpose of this paper is to develop a model for DDDM to be used by decision-makers in 3PLs and the supply chain industry. The model will contribute towards maximising the usage of data to make better informed decisions on how to manage and transform 3PL and supply chain enterprises. The sections contained in this paper are: Sections 1 and 2 provide the background and problem description. Section 3 explains the research method that was used in the study. In Section 4, the literature review findings and model development are explained. The last section of this paper presents the conclusions of the study.

\section{Background to Data Driven Decisions in 3PLs and Supply Chain Industry}

Recent developments in IS such as blockchain computing, cloud computing, social networking and wireless communication have improved the methods by which data is distributed and the way supply chains are structured. Researchers have recognised that IS innovations in the supply chain can benefit enterprises by providing real-time visibility, improved flexibility to react to unforeseen changes in the activities carried out by the supply chain players and efficient data exchange [13]-[15]. 3PLs are examples of the players in the supply chain industry and they offer outsourced logistics and warehousing services that mainly involve procurement and fulfilment activities [16]. Fig. 1 illustrates the typical flows of data and information for a 3PL company, relative to the other supply chain players. The arrows in the diagram depict that the data flows in two directions i.e. from the other supply chain players into the 3PLs as well as from the 3PLs to the other parties. Supply chain players can therefore serve as data sources to these parties. Warehouses and warehouse ISs collect data that can be shared with the rest of the 3PLs. Sensory devices installed on carriers like ships and delivery trucks also serve as data sources that can be shared with the 3PLs. 


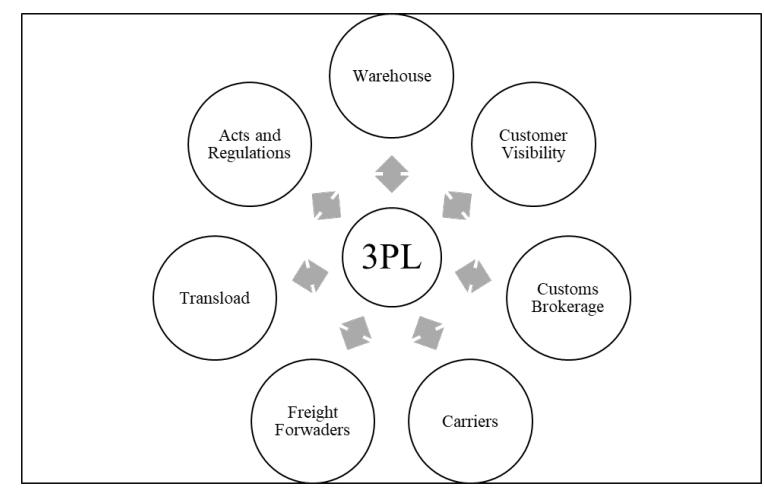

Fig. 1. Flow of Data between 3PLs and the rest of the Supply Chain (Adapted from [17])

The latest generation of ISs provides a high level of supply chain process integration through internet-based applications, thus serving as an additional source of integrated data that can be used for analysis [18]. An increase in the supply chain complexity has elevated the degree of uncertainty and risks that supply chain and 3PLs are faced with [19]. The rapid changes experienced by companies in this industry require a rapid analysis of the available data to make sound and rapid decisions $[15,16]$. For enterprises in the supply chain to benefit from DDDM, it is important for the decision-makers to understand the relationship of data and related data concepts like data quality and data sources and to understand the principles of discovering insights from the data collected [12]. DDDM in a 3PL refers to decision-makers systematically collecting and analysing data to guide a range of decisions that enable and improve the success of providing the outsourced services to their clients [9]. 3PLs using DDDM can therefore differentiate themselves within the supply chain industry and they are twice as likely to be top performers than lower performers [3]. However, in the 3PL and supply chain domain DDDM is rarely evident and DDDM models and frameworks specific to this domain are limited and do not consider all the stages of the DDDM process or process integration of 3PLs [18].

\section{Research Method}

This study follows the Design Science Research (DSR) methodology [22] and this paper reports on some aspects of the first three phases of DSR, which are 1) problem identification and motivation; 2) define the objectives of a solution and 3) design and development. The purpose of this paper is to design a model for DDDM that can provide guidance to decision-makers in the domain of 3PLs and the supply chain industry. To achieve this purpose the research method used was a literature review, which was conducted in two phases: (1) firstly to determine the objectives and requirements of for a DDDM model that relates to the 3PL and supply chain context and (2) secondly to identify existing frameworks and models for DDDM, particularly in the 3PM and supply chain domain. Literature searches were conducted on keywords, titles and abstracts of publications and were conducted in digital libraries including the ACM, Scopus, ScienceDirect and SpringerLink. The findings of the first phase are reported on in Section 2 of this paper whilst those of the second phase are reported on in Section 4. In accordance with the iterative nature of DSR, the feedback from this paper will be used to improve the model and the other phases of the research. In the next phases of the study, feedback from decision makers in the 3PL industry will be obtained to confirm the identified problems and to evaluate and improve the model. 


\section{$4 \quad$ Review Findings}

From the review of the literature seven DDDM models/frameworks were identified. The Cynefin Framework (Fig. 2) aids with decision-making [23] and categorises problems into four categories, namely ordered (either simple or complicated), complex and chaotic [24]. There is also a fifth type called 'disorder' which represents the situation when you don't know which of the other four applies to your situation. The Cynefin framework can help decision-makers in identifying the context of the problems they are required to solve so that they can not only make better decisions but also avoid the problems that arise when their preferred decision-making processes results in actions without the desired outcomes.

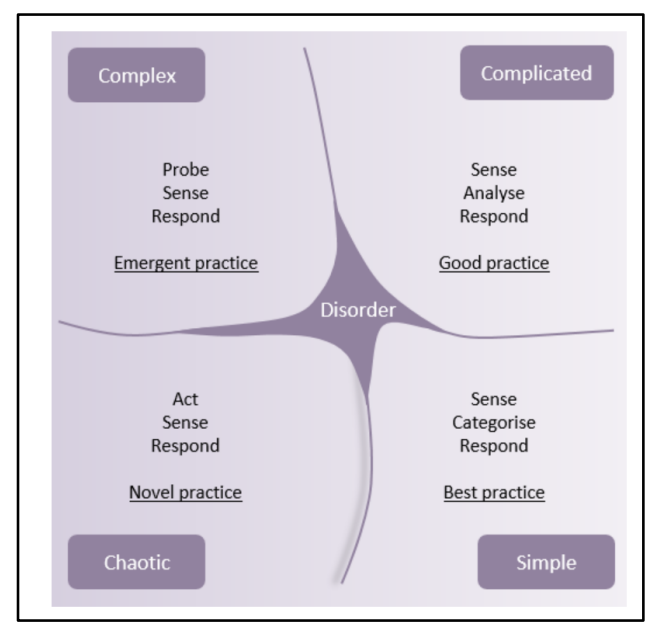

Fig. 2. Cynefin Framework [24]

A Framework for Simple versus Complex DDDM was proposed by [25], which provides a guideline on how variations in DDDM can be conceptualised along two continua namely; the type of data used and the nature of the data analysis and decision-making (Fig. 3). The authors suggest that the evaluation of the appropriateness of a type of DDDM should be done on a case-by-case basis. Demands for DDDM in enterprises often imply that data use is a relatively straightforward process. As such, enterprises fail to acknowledge the various ways in which decision-makers use and make sense of available data to inform decisions and actions. A DDDM process can fall within one of four quadrants depending on the level of complexity along the two continua. The four DDDM quadrants are (I) basic (II) analysisfocused (III) data-focused and (IV) inquiry-focused. Basic DDDM entails using simple data and simple analysis procedures. On the other extreme end, inquiry-focused DDDM (quadrant IV) entails using complex data and complex analysis to inform decision-making, which is better utilised for continuous enterprise improvement and to answer questions that do not have immediate answers. 


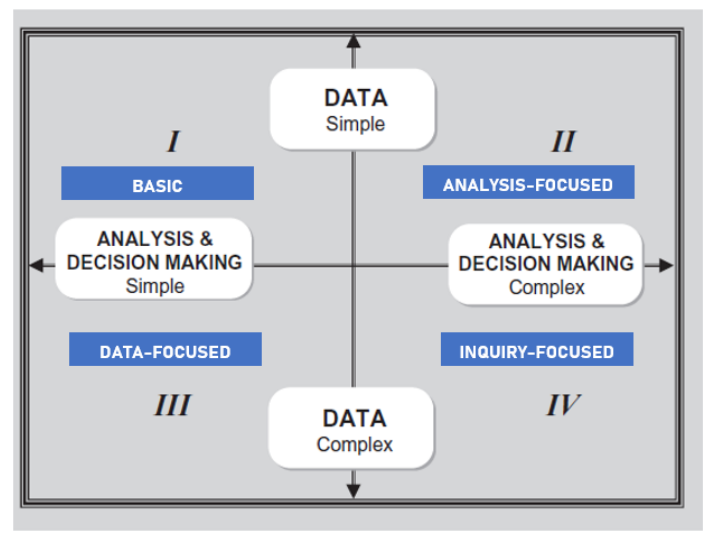

Fig. 3. Framework for Simple vs Complex DDDM. Adapted from [25]

In addition to the framework [25] identified seven factors that affect the success of DDDM, namely: resource capacity and expertise; analytical skills and support; accessibility and timeliness of data; perceived validity of the data; timeframe for the actions from the decisions made; partnerships with external enterprises; tools; and enterprise culture and leadership. Further work by [26] identified the factors promoting and hindering DDDM in an educational context and proposed that data use is influenced by three types of characteristics: organisation, data and user (Fig. 4). The organisational characteristics relate to enhancing data use by having a shared vision, leadership, support and collaboration. Data factors relate to accessibility, usability and quality of data. The user characteristics relate to knowledge and skills in the enterprise for data analysis and dispositions of the user to use the data. A structured method for analysis and interpretation of data on which to draw insights and base actions should also be adopted. The conclusions drawn in the study by [26], although conducted in an educational context, can be applied in a business context.

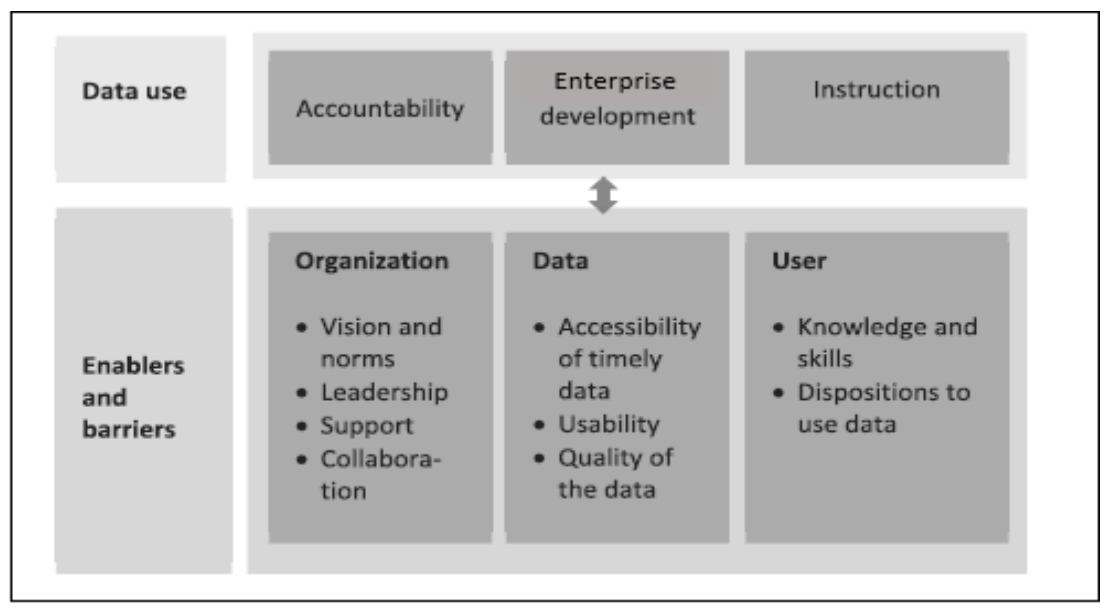

Fig. 4. Factors promoting or hindering DDDM [26]

The conceptual framework (Fig. 5) for DDDM argues that regardless of the position of the decisionmakers within the industry, data must be collected and organised into knowledge [27]. Synthesis and visualisation of the information then results in knowledge that can be used to make decisions. After the decision is implemented, the impact must be evaluated to improve the process of DDDM further. 


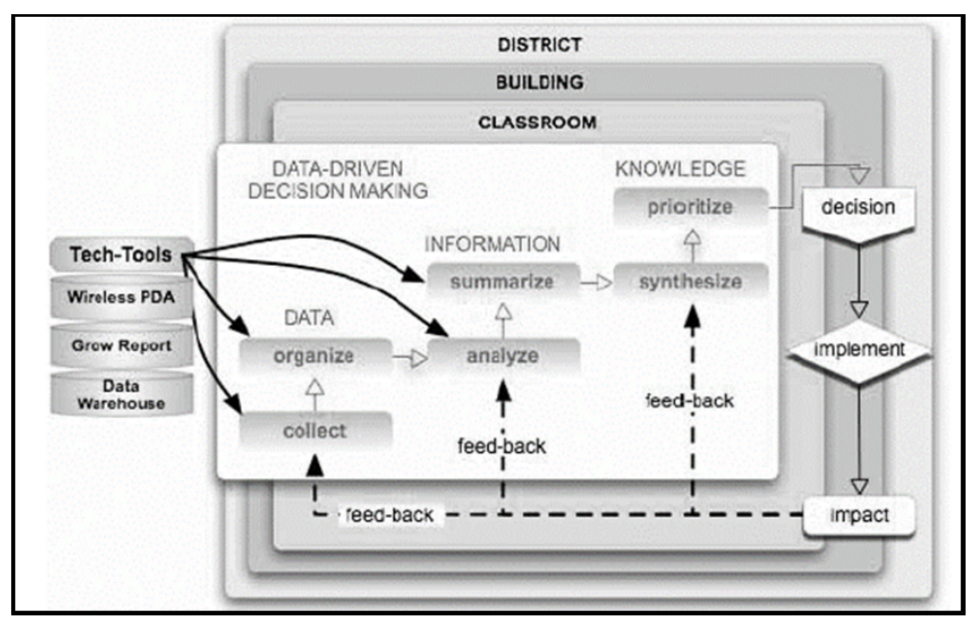

Fig. 5. A Theoretical Framework for Data-Driven Decision Making [27]

Both [9] and [28] argue that data lies at the core of an enterprise's decision-making and propose steps to be followed for DDDM. Whilst [9] proposes 10 steps, [28] provides a more summarised version in five steps (Fig. 6). The first of the five steps is for decision makers to formulate the enterprise's strategy and to map the direction on how data will be used to derive insights for better-informed decisions [28]. The second step is to identify key areas that are crucial in achieving the overall business strategy. These areas will serve as the domain focus and in the third step the target data sets should be identified, from which insights can be retrieved to solve the identified issues. The fourth step is to collect and analyse the data, from which actionable insights will be derived, thus achieving DDDM. The limitations to Roth's [28] five steps to DDDM are that the steps are expressed in broad terms and assumed to be applicable to any enterprise across all industries. Thus, the steps are not domain or industry specific. Furthermore, the five-step prescription does not highlight the importance of categorising the business decisions into categories as proposed by the Cynefin Framework [29].

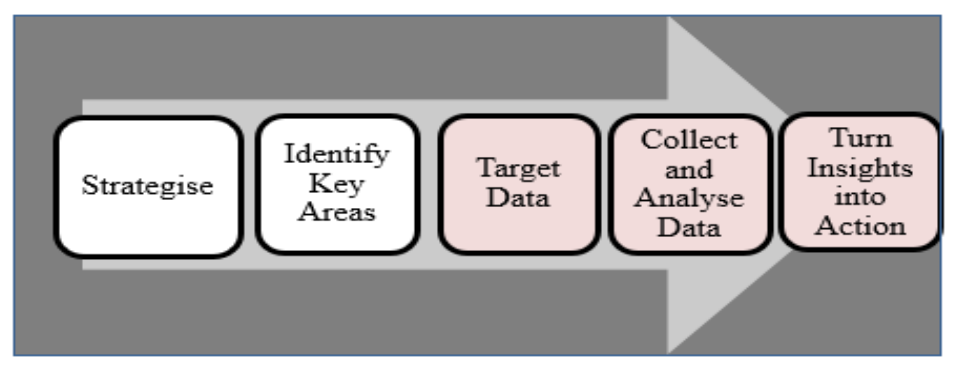

Fig. 6. Five Steps to Data-Driven Business Decisions [28] 
Table 1. Limitations and Contributions of DDDM Models/Frameworks

\begin{tabular}{|c|c|c|c|}
\hline Author & Title & Limitations & Contributions \\
\hline [23] & $\begin{array}{l}\text { The Cynefin } \\
\text { Framework }\end{array}$ & $\begin{array}{l}\text { Designed for } \\
\text { management decision } \\
\text { making. }\end{array}$ & $\begin{array}{l}\text { Classification of a decision based on } \\
\text { the level of its complexity (ordered, } \\
\text { complex, chaotic). }\end{array}$ \\
\hline$[25]$ & $\begin{array}{l}\text { Framework for } \\
\text { Simple vs } \\
\text { Complex DDDM }\end{array}$ & $\begin{array}{l}\text { Lack of context and } \\
\text { industry application. }\end{array}$ & $\begin{array}{l}\text { Types of data, data analysis and } \\
\text { decisions. } \\
\text { Seven factors affecting DDDM (e.g. } \\
\text { resources, skills). }\end{array}$ \\
\hline$[26]$ & $\begin{array}{l}\text { Factors fostering } \\
\text { and hindering } \\
\text { DDDM in schools }\end{array}$ & $\begin{array}{l}\text { Applied to the } \\
\text { education domain } \\
\text { only. }\end{array}$ & $\begin{array}{l}\text { Factors fostering and hindering DDDM } \\
\text { in schools (vision, resources, data } \\
\text { quality). }\end{array}$ \\
\hline$[27]$ & $\begin{array}{l}\text { A Theoretical } \\
\text { Framework for } \\
\text { DDDM }\end{array}$ & $\begin{array}{l}\text { Education domain } \\
\text { only. } \\
\text { No implementation of } \\
\text { the framework. }\end{array}$ & $\begin{array}{l}\text { Data }->\text { information }->\text { knowledge -> } \\
\text { decision }->\text { implement }->\text { impact. }\end{array}$ \\
\hline [9] & $\begin{array}{l}\text { DDDM: } 10 \\
\text { Simple Steps for } \\
\text { Any Business }\end{array}$ & $\begin{array}{l}\text { Lack of context and } \\
\text { industry application. } \\
\text { White paper. }\end{array}$ & 10 Steps to DDDM. \\
\hline$[28]$ & $\begin{array}{l}\text { Five Steps to } \\
\text { Data-Driven } \\
\text { Business } \\
\text { Decisions }\end{array}$ & $\begin{array}{l}\text { No classification of } \\
\text { complexity. } \\
\text { Steps are not industry } \\
\text { specific and lack } \\
\text { rigor. } \\
\text { Lessons learnt not } \\
\text { considered for future } \\
\text { decision-making. }\end{array}$ & $\begin{array}{l}\text { Five steps to DDDM (strategise, key } \\
\text { areas, target data, collect/analyse data, } \\
\text { insights/action). }\end{array}$ \\
\hline$[30]$ & $\begin{array}{l}\text { Decision } \\
\text { Requirements } \\
\text { Diagram (DRD) }\end{array}$ & $\begin{array}{l}\text { Discussion limited to } \\
\text { the decision-making } \\
\text { aspect of DDDM } \\
\text { only, with a limited } \\
\text { reference to the data } \\
\text { aspect. }\end{array}$ & $\begin{array}{l}\text { An iterative approach to defining the } \\
\text { requirements for decision-making in } \\
\text { DDDM. } \\
\text { A DRD allows for clarifying the } \\
\text { context when practising DDDM. }\end{array}$ \\
\hline
\end{tabular}

\section{$5 \quad$ Proposed DDDM Model for 3PLs}

The proposed DDDM model for 3PLs is built based on the guidelines provided by the existing frameworks, guidelines and models for DDDM presented in Section 4 and the requirements for the 3PL and supply chain domain highlighted in Section 3. From the existing DDDM models and frameworks,

it can be argued that the DDDM process constitutes of three primary phases as shown in

Fig. 7: (1) a preparation or setup phase (2) an execution phase and (3) a learning phase.

Setup Phase: To setup a 3PL for DDDM, the decision-makers should have data, process and decision-making knowledge. Inputs of the setup phase include existing domain knowledge and decision-makers' expertise, the need for decision-making and the desired outcomes of the decision. As proposed in the work by [27], [9] and [28], the process of DDDM begins with a skilled and analytical 
team of decision-makers identifying the data from which the insights will be drawn from. The data from all possible 3PL sources as specified by [17]) (Fig. 1) should therefore be identified. Next the data should be collected and stored by the Business Intelligence or data analytics team. The management of the data should be enterprise-wide, integrate supply chain processes [18] and adhere to data quality and governance principles [12] such as ISO 25012:2008. Thereafter, the data should be rapidly processed, analysed and visualised to gain a general understanding and description of the data $[15,16]$. There are various data analytics techniques that can be applied to build models from the data available in the supply chain [4]. The techniques include machine learning and data mining techniques (clustering, classification, regression and association rules), text analysis, social network analysis and sentiment analytics [31]. The data analytics techniques to be applied are chosen based on the objectives of the model and the type of data available. Subsequently, data sets for testing, training, and production purposes are developed and the model is built and executed [32,33]. Data knowledge incorporates the provisions of the first four steps in [28]'s five Steps to DDDM and the first eight Steps in [9]'s 10 Steps to DDDM.

Decision-makers in a 3PL consider their enterprises and the supply chain industry to identify and to understand the decision to be made and classify the decision into operational, tactical or strategic. Furthermore, the requirements of the decision are identified and in the case of DDDM, the data and the insights required to support the decision will form part of the requirements. There is therefore a twoway relationship between data knowledge and decision-making knowledge. To identify the decisions, their requirements and the complexity of the decisions, a framework such as the Cynefin framework should be considered. By using this framework, the decision is presented in a clear and unambiguous way and is classified into one of five categories. To facilitate the communication between the analytics team and the decision-makers in the 3PL, a Decision Requirements Diagram (DRD) is developed and communicated between these two divisions. The building of a DRD is performed by applying iteratively four steps proposed by [30] which are (1) identify decisions; (2) describe decisions; (3) specify decision requirements; and (4) decompose and refine the model. The four steps are iterated until the decisions are completely specified and the decision-makers have a clear sense of how the decision will be made. The input of the DRD is the data from which the insights will be derived; for example from carriers, warehouses and other sources in the supply chain as shown in Fig. 1. The outputs of the setup phase in DDDM are a DRD and knowledge and insights of the data used. Data knowledge is achieved from the discovery of relationships between the data and relevant insights from the data collected and analysed by the data analytics team [12].

Execution Phase: The DRD, the data knowledge and insights from the setup phase are used as inputs into the execution phase. Based on these, decision-makers devise decision alternatives as well as outcomes. Furthermore, they determine the relevance and the impact of the identified alternatives. In addition, the what-if scenarios, reporting, dashboards, simulation of solutions and other techniques can be used to evaluate these alternatives [33]. Possible courses of action are derived, developed and analysed to determine their suitability in making the decision and achieving the favoured outcome. Based on the models presented by the analytics team, decision-makers rely in the insights to make the decisions. After defining the alternatives and criteria for evaluation, these alternatives are evaluated to determine the impact that each one of them will have on business. A Decision-Support System (DSS) may be used to predict such relevance and outcomes of the various decision alternatives identified [34]. Based on the evaluation findings, decision makers choose an alternative or a set of alternatives that will solve the identified problem. During this phase, new information and knowledge may be derived to further refine the decision. The outputs of the execution phase are selected alternatives of the decision and an evaluation of their relevance and impact immediately before implementation. 
A Data-Driven Decision-Making Model for the Third-Party Logistics (3PL) Industry F. Moyo et al.

Learning Phase: It is extremely important in a DDDM process to acknowledge its effectiveness and that DDDM is more than data and infrastructure, it is also a process and a culture [35]. It is therefore important to have a phase (termed here as the learning phase) whereby process decision-makers use the lessons learnt from the DDDM process and the outcomes of the decisions made to improve the process and share the knowledge with the rest of the enterprise and the industry partners within the supply chain. Thereafter there is a need to invest in the necessary infrastructure and to motivate a culture shift within the enterprise. The process of making data-driven decisions can be analysed and reused in different decision-making instances within 3PLs and the supply chain industry. To achieve DDDM in 3PLs and the supply chain industries, it is therefore important to raise awareness at senior management levels and to foster a collaborative style of decision-making [36]. 
A Data-Driven Decision-Making Model for the Third-Party Logistics (3PL) Industry F. Moyo et al.

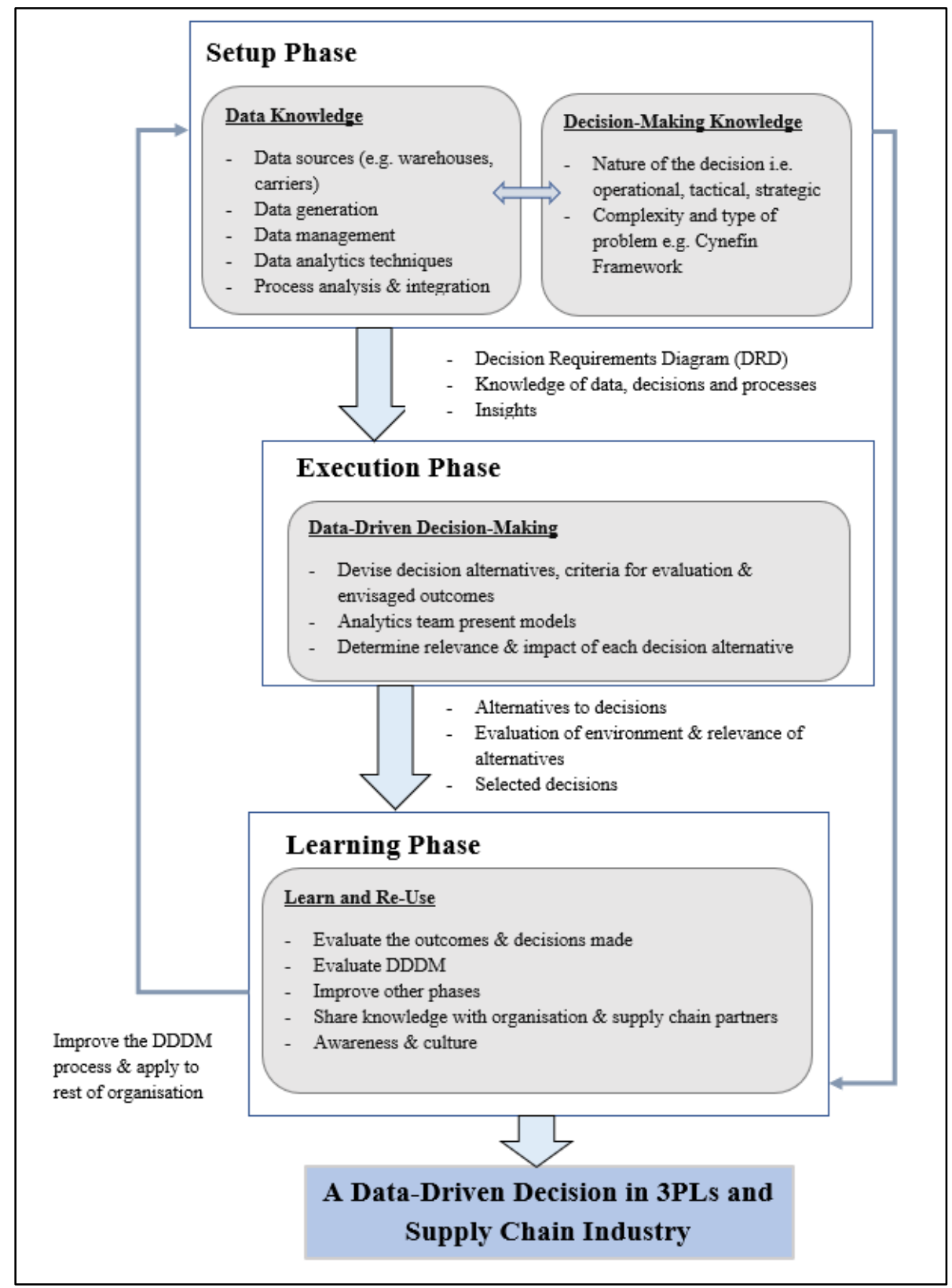

Fig. 7. A Data-Driven Decision-Making Model for 3PLs

\section{Discussion}

This paper presents a theoretical model that can guide decision-makers in 3PLs on how to incorporate data into the decision-making process. The differences between the DDDM model and other existing models and frameworks for DDDM are: 
- Assumptions and constraints on which the model depends on more comprehensive, rigorous and relevant to the 3PL and supply chain industry;

- The model incorporates the categories of problems and decisions based on those used in the Cynefin framework to encourage a level of deliberation in the cognitive processes involved in decision-making; and

- The DDDM model will be evaluated for effectiveness and the lessons learnt will be systematically fed back to the rest of the 3PL enterprise and industry.

The model will facilitate the communication between the decision-makers and the analytics team in the decision-making process, which can lead to more efficient and effective use of data analytics and thus benefit from the insights derived from data for decision-making. The documentation of the decision-making process in the format of a DRD will enable 3PLs to reuse knowledge for future decision-making, fostering learning from the decisions made.

\section{Conclusions}

Knowledge and insights retrieved from data available internally and externally in the supply chain and 3PL industry has the potential to improve the decision-making process, thus improving the quality of the decisions made and achieving a competitive advantage for these enterprises. The findings of this study attempt to aid decision-makers in 3PLs to maximise the capabilities provided by data by presenting a prescriptive, theoretical model for DDDM. The model integrates data analytics into the phases of the decision-making process. The model was designed built based on two elements. Firstly from literature existing frameworks and models for DDDM and secondly from studies on the problems and requirements of the 3PL and supply chain industry. Limited studies on DDDM in this industry were found that were comprehensive and classified problems and decisions as guided by the Cynefin framework, nor were they specific to the industry. The main contribution of the study is therefore a comprehensive DDDM model that could be used in a supply chain and 3PL context and provide guidelines that can assist with facing the challenges in this industry. Limitations of this study are that the research was exploratory and the proposed model is theoretical thus, lacks any empirical evaluation. Whilst the model is theoretical, future work of this study will include an evaluation of the proposed model by decision-makers in the 3PL and supply chain industries. 
A Data-Driven Decision-Making Model for the Third-Party Logistics (3PL) Industry F. Moyo et al.

\section{References}

[1] G. Büyüközkan and F. Göçer, "Digital Supply Chain: Literature review and a proposed framework for future research," Comput. Ind., vol. 97, pp. 157-177, 2018.

[2] M. Long and J. Langley, "2018 22nd Annual Third-Party Logistics Study: The State of Logistics Outsourcing,” 2018.

[3] S. LaValle, M. . Hopkins, E. Lesser, R. Hockley, and N. Kruschwitz, "Analytics : the new path to value. MIT Sloan Management Review," 2010.

[4] McKinsey \& Company, "Big data and the supply chain: The big-supply-chain analytics landscape (Part 1)," 2016. [Online]. Available: https://www.mckinsey.com/businessfunctions/operations/our-insights/big-data-and-the-supply-chain-the-big-supply-chainanalytics-landscape-part-1. [Accessed: 26-Jun-2019].

[5] V. C. S. Chen, Hsinchun, Roger H. L. Chiang, "Special_Issue_Business_Intelligence_Rese," Mis Q., vol. 36, no. 4, pp. 1165-1188, 2012.

[6] R. Sharma, S. Mithas, and A. Kankanhalli, "Transforming decision-making processes: a research agenda for understanding the impact of business analytics on organisations," Eur. J. Inf. Syst., vol. 23, no. 4, pp. 433-441, 2014.

[7] D. Blackwell, "Equivalent Comparisons of Experiments," Ann. Math. Stat., vol. 24, no. 2, pp. 265-272, 1953.

[8] Q. Long, "Knowle dge-Base d Systems Data-driven decision making for supply chain networks with agent-based computational experiment," Knowledge-Based Syst., vol. 141, pp. 55-66, 2018.

[9] B. Marr, "Data-Driven Decision Making: 10 Simple Steps For Any Business," Forbes, 2016. [Online]. Available: https://www.forbes.com/sites/bernardmarr/2016/06/14/data-drivendecision-making-10-simple-steps-for-any-business/\#9a420955e1e5. [Accessed: 16-Apr-2019].

[10] L. Angria S, Y. Dwi Sari, M. Zarlis, and Tulus, "Data-driven Modelling for decision making under uncertainty," IOP Conf. Ser. Mater. Sci. Eng., vol. 300, no. 1, 2018.

[11] M. Ghasemaghaei, S. Ebrahimi, and K. Hassanein, "Data analytics competency for improving firm decision making performance," J. Strateg. Inf. Syst., vol. 27, no. 1, pp. 101-113, 2018.

[12] F. Provost and T. Fawcett, "Data Science and its Relationship to Big Data and Data-Driven Decision Making," Big Data, vol. 1, no. 1, pp. 51-59, 2013.

[13] A. E. Coronado Mondragon, C. S. Lalwani, E. S. Coronado Mondragon, and C. E. Coronado Mondragon, "Facilitating multimodal logistics and enabling information systems connectivity through wireless vehicular networks," Int. J. Prod. Econ., vol. 122, no. 1, pp. 229-240, 2009.

[14] A. Gunasekaran and S. C. Lenny Koh, "Interlocking of information systems for international supply and demand chains management," Int. J. Prod. Econ., vol. 122, no. 1, pp. 127-132, 2009.

[15] A. Perego, S. Perotti, and R. Mangiaracina, "ICT for logistics and freight transportation: a literature review and research agenda," Int. J. Phys. Distrib. Logist. Manag., vol. 41, no. 5, pp. 457-483, 2011. 
A Data-Driven Decision-Making Model for the Third-Party Logistics (3PL) Industry F. Moyo et al.

[16] M. Rouse, "3PL (third-party logistics)," Supply Chain Planning and Execution, 2018. [Online]. Available: https://searcherp.techtarget.com/definition/3PL-third-party-logistics. [Accessed: 25-Jun-2019].

[17] Tigers Global Logistics, "Manage your Supply Chain in One Place," Tigers Logistics, 2018. [Online]. Available: https://www.go2tigers.com/services/. [Accessed: 15-Apr-2019].

[18] A. Robinson, "How Supply Chain Systems Integration Is a Game Changer," Industry Week, 2018. [Online]. Available: https://www.industryweek.com/supply-chain/how-supply-chainsystems-integration-game-changer. [Accessed: 25-Jun-2019].

[19] I. Manuj and J. T. Mentzer, "Global supply chain risk management strategies," Int. J. Phys. Distrib. Logist. Manag., vol. 38, no. 3, pp. 192-223, 2008.

[20] Danah Boyd and K. Crawford, "CRITICAL QUESTIONS FOR BIG DATA," Information, Commun. Soc., vol. 15, no. 5, pp. 662-679, 2012.

[21] A. McAfee and E. Brynjolfsson, "Big Data: The Management Revolution," Harv. Bus. Rev., vol. 90, pp. 60-66,68,128, 2012.

[22] K. Peffers, T. Tuunanen, M. Rothenberger, and S. Chatterjee, "A Design Science Research Methodology for Information Systems Research,” J. Manag. Inf. Syst., vol. 24, no. 3, pp. 4577, Dec. 2007.

[23] G. Kempermann, "Cynefin as reference framework to facilitate insight and decision-making in complex contexts of biomedical research," Front. Neurosci., vol. 11, no. NOV, pp. 1-8, 2017.

[24] D. J. Snowden and M. E. Boone, “A Leader’s Framework for Decision Making,” Harvard Business Review- Decision Making, 2007. [Online]. Available: https://hbr.org/2007/11/aleaders-framework-for-decision-making. [Accessed: 16-Jul-2019].

[25] G. S. Ikemoto and J. A. Marsh, "chapter 5 Cutting Through the 'Data-Driven' Mantra: Different Conceptions of Data-Driven Decision Making," Yearb. Natl. Soc. Study Educ., vol. 106, no. 1, pp. 105-131, 2007.

[26] K. Schildkamp, C. Poortman, H. Luyten, and J. Ebbeler, "Factors promoting and hindering data-based decision making in schools," Sch. Eff. Sch. Improv., vol. 28, no. 2, pp. 242-258, 2017.

[27] E. B. Mandinach, M. Honey, and D. Light, "Mandinach, E. B., Honey, M., \& Light, D. (2006). A Theoretical Framework for Data-Driven Decision Making, 1-18.," A Theor. Framew. DataDriven Decis. Mak., pp. 1-18, 2006.

[28] E. Roth, "5 Steps to Data-Driven Business Decisions," Sisense, 2018. [Online]. Available: https://www.sisense.com/blog/5-steps-to-data-driven-business-decisions/. [Accessed: 16-Apr2019].

[29] Ö. Göçer and M. S. Derindere, "Cynefin Framework for Decision Makers for Information Systems Security in the face of Information Asymmetry," Istanbul J. Innov. Educ., vol. 1, no. 1, pp. 1-13, 2015.

[30] Decison Management Solutions, "An Introduction to Decision Modeling with DMN," p. 13, 2016.

[31] N. Elgendy and A. Elragal, "Big Data Analytics in Support of the Decision Making Process," 
A Data-Driven Decision-Making Model for the Third-Party Logistics (3PL) Industry F. Moyo et al.

Procedia Comput. Sci., vol. 100, no. June 2017, pp. 1071-1084, 2016.

[32] D. Dietrich, B. Heller, B. Yang, and EMC Education Services, Data science \& big data analytics: Discovering, analyzing, visualizing and presenting data. 2015.

[33] F. Chiheb, F. Boumahdi, and H. Bouarfa, "A New Model for Integrating Big Data into Phases of Decision-Making Process," Procedia Comput. Sci., vol. 151, no. 2018, pp. 636-642, 2019.

[34] T. Poleto, V. D. H. de Carvalho, and A. P. C. S. Costa, "The Roles of Big Data in the DecisionSupport Process: An Empirical Investigation,” in ICDSST, 2015.

[35] G. Anadiotis, "Business analytics: The essentials of data-driven decision-making," ZDNet, 2018. [Online]. Available: https://www.zdnet.com/article/business-analytics-the-essentials-ofdata-driven-decision-making/. [Accessed: 16-Apr-2019].

[36] Business Application Research Center, "14 Survey-Based Recommendations on How to Improve Data-Driven Decision-Making," BI-Survey.com, 2018. [Online]. Available: https://bisurvey.com/data-driven-decision-making-business. [Accessed: 17-Apr-2019]. 